\title{
A importância da identificação botânica nos inventários florestais: o exemplo do "tauari" (Couratari spp. e Cariniana spp. - Lecythidaceae) em duas áreas manejadas no estado do Pará1
}

\author{
Lílian Costa PROCÓPIO², Ricardo de Souza SECCO3 \\ RESUMO
}

O nome vulgar adotado nos inventários florestais tem agrupado espécies distintas. Para exemplificar este problema, foram avaliadas as identificaçôes de indivíduos comercialmente determinados como "tauari" em inventários de duas áreas manejadas de 100 ha nos pólos madeireiro central e leste do Estado do Pará. Características dendrológicas de cada espécie foram anotadas para diferenciá-las. Dados sobre a distribuição geográfica dessas espécies, as propriedades tecnológicas de sua madeira e a legislação atual para o manejo florestal são discutidos. O inventário feito no pólo madeireiro central registrou 112 indivíduos de "tauari" nominados como Couratari guianensis, e seis indivíduos de "tauari-cachimbo" determinados como Couratari sp. Depois de uma revisão botânica com material coletado de cada árvore, foi constatado que os indivíduos determinados como Couratari guianensis agrupavam três espécies: Couratari guianensis, C. oblongifolia e C. stellata, esta última com maior densidade relativa. O que antes constava como Couratari sp. agrupava as espécies Cariniana micrantha e Cariniana decandra. No pólo leste, o inventário contava 33 indivíduos, listados como "tauari" ou Couratari guianensis. Para estes, a identificação botânica mostrou o agrupamento de duas espécies: C. guianensis com maior densidade relativa e C. oblongifolia. Fora da área de estudo, foi registrada a ocorrência de $C$. tauari. Este estudo mostra que é possível separar as espécies utilizando aspectos dendrológicos (folhas, ramos e tronco). O inventário botânico é demonstrado como base para o conhecimento da diversidade e indispensável para assegurar o sucesso dos planos de manejo. No contexto jurídico, o agrupamento inviabiliza o cumprimento das leis brasileiras referentes ao manejo.

PALAVRAS CHAVES: Inventário florestal; dendrologia; diversidade, madeira.

\section{The importance of botanical identification in forest inventories: the example of "tauari" - Couratari spp. and Cariniana spp., Lecythidaceae - in two timber areas of the State of Pará}

\begin{abstract}
The vernacular names usually used in commercial inventories may group together distinct species. To investigate this problem, the botanical identification of trees called Tauari were examined were examined in commercial inventories of 100 ha located in the central and eastern lumber regions of the State of Pará. Field characters of each species were noted. Information about the relative distribution of this species, the technological characteristics of the timber of each species and Brazil's federal laws relating to forest management is discussed. In the central region, 112 individuals were recorded as Couratari guianensis and six individuals as Couratari sp. After revision, using botanical material collected from each tree and identified using herbarium material, the following species listed as Couratari guianensis were found: Couratari guianensis, C. oblongifolia and C. stellata (the most abundant) and specimens listed as Couratari sp. included both Cariniana micrantha and C. decandra. In the eastern region, 33 individuals were recorded by the company as Couratari guianensis, but the scientific identification showed the existence of two species: C. guianensis (the most abundant) and C. oblongifolia. C. tauari also was seen growing nearby. This study shows that correct determination of the can be obtained from field characters (leaves, branches and trunks). Botanical identification is demonstrated as fundamental for the knowledge of the regional diversity and essential for successful management plans.
\end{abstract}

KEY WORDS: Forest inventory; dendrology; diversity of plants, timber.

\footnotetext{
1 Este trabalho integra o Projeto Dendrogene executado pela Embrapa Amazônia Oriental gerido pelo Department for International Development -DFID - (www.cpatu.embrapa.br/ dendro.htm) e compõe parte da dissertação do primeiro autor.

2 Aluna de doutorado INPA/CPEC. Av. André Araújo, 2936 Aleixo. e-mail: Icprocopio@inpa.gov.br
}

3 Pesquisador do Departamento de Botânica do Museu Paraense Emílio Goeldi. e-mai: rsecco@museu-goeldi.br 


\section{INTRODUÇÃO}

O inventário florestal é a base do plano de manejo e da produção de uma empresa madeireira. Este deve fornecer, além do volume total explorável, a distribuição do número de árvores por hectare e por classe de diâmetro; área basal por hectare, por classe de diâmetro, por grupo de espécies e para cada espécie individualmente (Silva, 2001) o que torna possível prever gastos e lucros para a indústria madeireira.

A avaliação da área a ser explorada é feita a partir da lista de espécies e da quantidade de espécimes encontrados. Através desta avaliação, os órgãos de fiscalização permitem ou não a exploração.

O método usual de inventário florestal conta com o conhecimento empírico de nativos conhecedores da área (mateiros), os quais adotam nome vernacular na determinação das espécies. Estas pessoas adquirem seus conhecimentos através de ensinamentos que passam de geração em geração, ou até criam nomes que os façam lembrar o "tipo" de árvore a qual querem fazer referência e nunca fazem coletas botânicas para conferência. O nome científico correspondente, listado pelas empresas madeireiras no inventário comercial geralmente vem de listas de nomes prováveis para o nome vernacular estabelecido pelo mateiro, proveniente de literatura especializa ou de listas do IBAMA. Esta correspondência de nomes é feita sem seguir critérios científicos, morfológicos ou ecológicos das espécies.

O uso do nome vernacular nos inventários florestais omite a verdadeira ocorrência geográfica das espécies, pois existe grande variação destes nomes associados à diferentes espécies e que mudam conforme a região, a cultura ou ao uso na comercialização (Martins-da-Silva, 2002). Uma espécie chega a ter até dez nomes vernaculares e existe ainda a relação de diversos nomes vernaculares para um mesmo táxon (Camargos et al. 2001; Martins-da-Silva, 2002). Kanashiro (2002) afirma que por serem semelhantes a olhos não-treinados, as espécies são confundidas e exploradas de forma desordenada e não sustentável, afirma também que a distinção das espécies de forma clara e didática é necessária para minimizar prejuízos econômicos e colaborar para o controle da manutenção da biodiversidade.

Tendo em vista a conservação das espécies florestais, o Ministério do Meio Ambiente (MMA, 2002) através da Instrução Normativa No 04 , estabelece critérios para a exploração sustentável da floresta. Um destes critérios determina que a definição do diâmetro mínimo de exploração deve considerar parâmetros ecológicos, como por exemplo, a regeneração natural, e o uso final de cada espécie. Estabelece ainda que o volume médio a ser extraído será aquele definido pelo inventário florestal 100\% (Cap. I. Art. 110 ), ou seja, pelo levantamento e identificação de todas as árvores da área a ser explorada, o que requer um inventário florestal que forneça informaçōes verídicas e consistentes.

Como evidência da problemática das múltiplas espécies conhecidas com um único nome ou derivaçōes, as espécies Couratari guianensis Aublet, C. oblongifolia Ducke \& Knuth, C. pulchra Sandwith e Cariniana micrantha Ducke são citadas como "tauari" na publicação Padronização da Nomenclatura Brasileira da Madeiras Tropicais Amazônicas (IBAMA, 1991). Mori \& Prance (1990) consideram C. pulchra como um sinônimo de Couratari guianensis.

Cada espécie madeireira tem suas características peculiares (como secagem, densidade, trabalhabilidade, contração, flexão, compressão, dureza, tração e cisalhamento) que define não somente seu uso final como também o processo de beneficiamento em pranchas prontas para comercialização. $\mathrm{O}$ agrupamento de várias espécies em um único nome torna inviável a correta definição de seu uso e conseqüentemente, gera incredulidade na relação vendedor-consumidor.

Com as espécies comercializadas como "tauari", a trabalhabilidade da madeira, por exemplo, tem seu resultado bastante influenciado pela presença de depósitos minerais nos seus poros. A sílica $\left(\mathrm{SiO}_{2}\right)$ ocorre naturalmente no interior dos elementos de raios e no parênquima axial do tronco como uma inclusão nos lumes das células (Burger \& Richeter, 1991). Vasconcelos et al. (1993) relatam que estas espécies apresentam elevado teor de sílica, podendo inviabilizar o processamento da madeira na conversão de toras em madeiras serradas, em virtude do seu efeito abrasivo sobre os elementos de corte. Para estas espécies são necessárias técnicas elaboradas para desdobro, como o uso de serras especiais e técnicas que evitem problemas como empenamento e rachadura durante os processos de aplainamento, fresamento, lixamento e furação (SUDAM/IPT, 1981).

Poucos trabalhos abordam as propriedades da madeira de espécies conhecidas como "tauari". Em dados do Projeto RADAM, na publicação Rendimento em Serraria de Trinta Espécies de Madeiras Amazônicas da Superintendência de desenvolvimento da Amazônia - SUDAM/IPT (1981), a utilização desta madeira é citada com o nome vernacular "tanarí", um provável erro de grafia.

O presente estudo foi desenvolvido com o objetivo de demonstrar a importância da identificação botânica correta, verificando a consistência dos inventários florestais atuais, listando espécies inventariadas como "tauari" em empresas madeireiras que realizam a exploração denominada de "baixo impacto". Outro objetivo foi analisar as conseqüências deste agrupamento no conhecimento da diversidade local e na comercialização destas espécies e por fim, fornecer a caracterização morfologica da planta viva, para distinção das espécies determinadas como "tauari" no Estado do Pará. 


\section{MATERIAL E MÉTODOS}

\section{LEVANTAMENTO PRÉVIO DAS ESPÉCIES CONHECIDAS COMO "TAUARI"}

Através de literatura específica e coleta de informações de exsicatas dos herbários indexados IAN (Embrapa Amazônia Oriental), MG (Museu Paraense Emilio Goeldi) e INPA (Instituto Nacional de Pesquisas da Amazônia), foram listadas as espécies conhecidas pela nomenclatura vernacular como “tauari”, ocorrentes no Estado do Pará.

\section{ÁREA DE ESTUDO}

Os inventários botânicos foram realizados em duas áreas de 100 ha. Uma, representando o pólo madeireiro leste do Estado do Pará (Veríssimo et al, 2002), cedida pela empresa Cikel Brasil Verde S/A, localizada no município de Paragominas, Fazenda Rio Capim, inserida numa unidade de produção anual (UPA) de 4000 ha, inventariada e explorada no ano de 2003. A outra área, cedida pelo IBAMA (Instituto Brasileiro de Meio Ambiente e dos Recursos Naturais Renováveis) representa o pólo madeireiro central do Estado (Veríssimo et al. 2002), localizada na Floresta Nacional do Tapajós (FNT), BR-163-Km 83, Município de Belterra, inserida numa UPA de 500 ha, inventariada e explorada em 2003 pela empresa madeireira Maflops (Fig. 1). De cada área foram tirados cerca de $20 \mathrm{~m}^{3} /$ ha do inventário total, ou seja, cerca de 4 árvores/ ha de diferentes espécies. Não foi feito o levantamento pósexploratório para conhecimento de remanescentes. Porém, as empresas registraram que indivíduos "tauari" foram selecionadas como matrizes, ou porta-sementes.

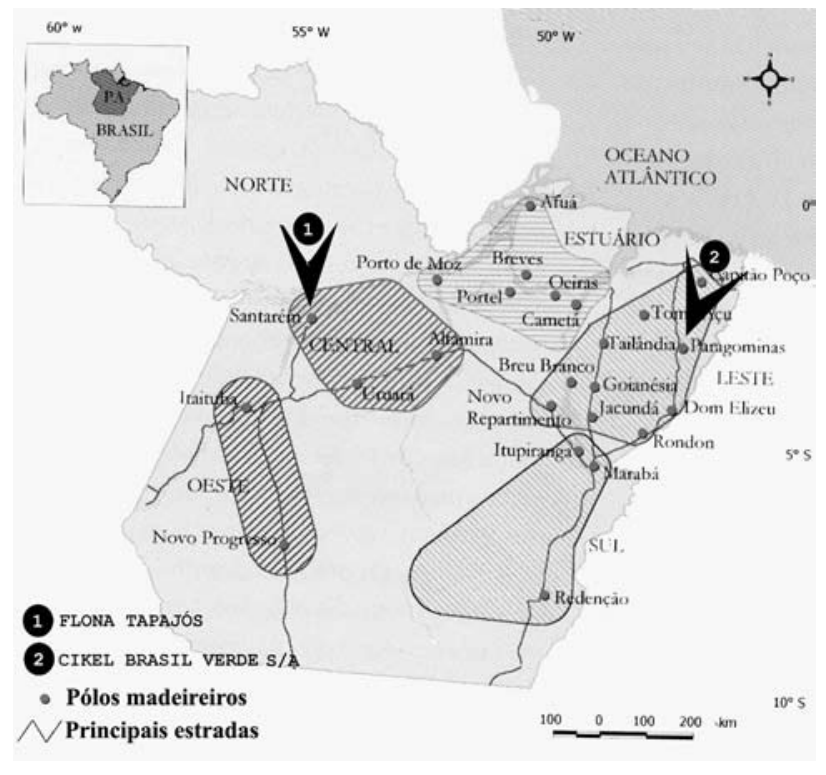

Figura 1 - Pólos madeireiros no Estado do Pará. Áreas de estudo localizadas no pólo Central (1) e Leste (2). Fonte: Verríssimo et al. (2002) com modificações.

\section{LEVANTAMENTO E IDENTIFICAÇÃO DAS ESPÉCIES}

As duas áreas de 100 ha. cada foram visitadas seguindo os inventários comerciais e as espécies inventariadas como tauari pelas empresas foram determinadas usando critérios taxonomicos. Foram feitas ainda, coletas aleatórias de "tauari" no entorno dos 100 ha demarcados.

Para constatar quais espécies estão sendo comercializadas, foram observados in loco todos os indivíduos determinados com o vernacular "tauari” com diâmetro à altura do peito (DAP) acima de $45 \mathrm{~cm}$. A coleta botânica para a identificação seguiu métodos tradicionais de prensagem, conservação. A identificação foi feita por comparação com amostras pré-determinadas por especialistas botânicos, depositadas nos herbários e com a caracterização descrita nas revisóes taxonômicas de Prance \& Mori (1979) e Mori \& Prance (1990). Foram considerados indivíduos estéreis e férteis (com flores e/ou frutos) para fins de identificação e confecção de exsicatas. As exsicatas férteis foram registradas e incorporadas à coleção dos herbários IAN (Instituto Agronômico do Norte), situado na Embrapa Amazônia Oriental e MG (Museu Goeldi), situado no Museu Paraense Emilio Goeldi. Foram feitas imagens em máquina fotográfica digital das exsicatas do material botânico coletado e dos indivíduos no campo, as quais foram enviadas para especialista que revisou e confirmou as identificações prévias. O levantamento taxonômico obtido foi comparado com o inventário comercial feito pelas empresas e comparado entre regiôes.

As descrições das exsicatas e dos aspectos e formas do fuste, casca e ramos, foram compiladas para compor a caracterização de campo das espécies seguindo a terminologia de Ribeiro et al. (1999). Esta caracterização foi utilizada na elaboração de uma chave de identificação com fotos elucidativas das espécies listadas nos inventários taxonômicos. As estruturas foram analisadas sob lupa manual e estereomicroscópio. As medidas que aparecem entre parênteses referem-se aos valores considerados extremos e menos freqüentes nos materiais analisados. Nas descrições das espécies são usadas as siglas: alt. - altura; ca. - cerca de, aproximadamente; compr. - comprimento; fi - Flor; fr - Fruto; st - estéril; FNT - Floresta Nacional do Tapajós; MG - Museu Goeldi (sigla do herbário do Museu Paraense Emilio Goeldi); IANInstituto Agronômico do Norte (sigla do herbário da Embrapa Amazônia Oriental). Na chave dicotômica o número que aparece na frente do nome da espécie refere-se à seqüência de sua descrição.

\section{LEVANTAMENTO DAS PROPRIEDADES E APTIDÕES DA MADEIRA}

Neste trabalho, foram consideradas como aptidóes tecnológicas, algumas propriedades físicas e mecânicas da madeira, mais especificamente, informaçōes sobre a secagem, a trabalhabilidade, densidade básica, retratibilidade 
(contração volumétrica), e dos testes mecânicos de resistência à flexão estática, compressão paralela às fibras, compressão perpendicular às fibras, resistência ao cisalhamento e dureza Janka. Tais dados foram adquiridos do laboratório de produtos florestais (LPF) do IBAMA (<www.ibama.gov.br/lpf/madeira/ caracteristicas $>$ acessado em setembro de 2003). Informações do conteúdo de sílica nos poros da madeira foram tomadas de Mori \& Prance (1990). É importante salientar que estas informações correspondem às espécies descritas, pois foram determinadas a partir de material botânico coletado, identificado e depositado em herbários indexados.

\section{RESULTADOS E DISCUSSÃO}

Comparação entre as listas levantadas nos herbários e na literatura botânica e a lista obtida a partir do inventário taxonômico

O levantamento preliminar das espécies denominadas "tauari" no Estado do Pará mostrou que um mesmo nome vulgar pode ser atribuído a várias espécies de plantas, bem como, uma mesma entidade taxonômica pode ter diferentes nomes populares. Allantoma lineata, segundo Camargos et al. (2001) é conhecida vulgarmente como "tauari" e "cerú". Porém, este último é o nome mais citado para esta espécie na literatura e nas madeireiras visitadas. "Cerú” também é citado por Camargos et al. (2001) para Cariniana decandra Ducke (Tab. 1). O nome mais comum encontrado nas madeireiras para as espécies de Cariniana foi castanha-de-macaco.

No inventário taxonômico do presente estudo constatamos que das oito espécies citadas na literatura como ocorrentes no Pará, somente seis, Cariniana decandra, Cariniana micrantha, Couratari guianensis, Couratari oblongifolia, Couratari stellata e Couratari tauari foram encontradas e estão sendo exploradas nas áreas dos pólos madeireiros central e leste do Estado (Tab. 1). As duas espécies, Allantoma lineata e Couratari tenuicarpa, não foram amostradas provavelmente por habitarem margens de rios, áreas onde o corte é proibido segundo as normas do manejo florestal de baixo impacto (MMA, 2002).

\section{COMPARAÇÃO ENTRE OS INVENTÁRIOS COMERCIAL E TAXONÔMICO}

No pólo madeireiro central, o inventário comercial feito pela empresa madeireira registrou 112 indivíduos de "tauari" e seis indivíduos de "tauari-cachimbo" para os quais a empresa adotou os nomes científicos Couratari guianensis e Couratari sp. respectivamente. $\mathrm{O}$ estudo taxonômico dos espécimes levantados mostrou a ocorrência de cinco espécies de Lecythidaceae. Para os indivíduos agrupados como C. guianensis "tauari" foram determinadas: 107 Couratari stellata, quatro $C$. oblongifolia e apenas um espécime de $C$. guianensis. Entre aqueles agrupados anteriormente como Couratari sp. "tauari-cachimbo", foram identificados quatro
Tabela 1 - Lista das espécies conhecidas como tauari no Estado do Pará, segundo os herbários IAN, MG e INPA e referências: Mori \& Prance (1990); Prance \& Mori (1979); Camargos et al. (2001). Espécies econtradas nas áreas estudadas.

\begin{tabular}{|c|c|}
\hline Espécie & $\begin{array}{l}\text { Áreas de ocorrência no Estado do } \\
\text { Pará }\end{array}$ \\
\hline $\begin{array}{l}\text { Allantoma lineata (Martius ex } \\
\text { O.Berg) Miers }\end{array}$ & $\begin{array}{l}\text { Ocorre de Manaus até o Oeste do } \\
\text { Pará. Nome vulgar mais freqüente: } \\
\text { cerú (Prance \& Mori, 1979). Citado } \\
\text { por Camargos et al. (2001) como } \\
\text { tauari }\end{array}$ \\
\hline Cariniana decandra Ducke* & $\begin{array}{l}\text { Sudoeste da Amazônia, Pará } \\
\text { (Rio Tapajós, Flechal, Bela Vista e } \\
\text { Santarém). Nome vulgar: cerú, tauari. }\end{array}$ \\
\hline Cariniana micrantha Ducke* & $\begin{array}{l}\text { No Pará, nas proximidades do Rio } \\
\text { Tapajós e Bela Vista. No Amazonas, } \\
\text { Rio Curuçá próximo de Maués. }\end{array}$ \\
\hline Couratari guianensis Aubl.* & $\begin{array}{l}\text { Pará, abrange toda Amazônia Oriental } \\
\text { e parte da Central. }\end{array}$ \\
\hline $\begin{array}{l}\text { Couratari oblongifolia Ducke \& } \\
\text { R. Knuth* }\end{array}$ & $\begin{array}{l}\text { Pará, incluindo Belém, Santarém, } \\
\text { Moju, Paragominas. }\end{array}$ \\
\hline Couratari stellata A.C. Sm.* & $\begin{array}{l}\text { Oeste do Estado do Pará (Santarém } \\
\text { e Belterra). }\end{array}$ \\
\hline Couratari tauari 0. Berg* & $\begin{array}{l}\text { Pará, Juriti Velho. Apenas amostra do } \\
\text { Tipo depositada no herbário IAN. }\end{array}$ \\
\hline Couratari tenuicarpa A.C. Sm. & $\begin{array}{l}\text { Próximo ao Rio Trombetas, Lago } \\
\text { Erepecu. Conhecida como Tauari- } \\
\text { do-igapó. }\end{array}$ \\
\hline
\end{tabular}

espécimes de Cariniana micrantha um de Cariniana decandra e um espécime de Sapotaceae, Pouteria sp. (Fig. 2). No entorno dos 100 ha amostrados observamos espécimes de Cariniana micrantha marcados pela empresa com outros nomes vulgares (cerú e quaruba-cedro). No pólo madeireiro leste, o inventário comercial feito pela empresa na área da Fazenda Rio Capim - Paragominas, registrou 33 espécimes de "tauari", para os quais adotou o nome científico Couratari guianensis. Após o estudo taxonômico foi constatado o agrupamento duas espécies: C. guianensis representada por 21 espécimes e C. oblongifolia com 12 espécimes (Fig. 3). Outras coletas feitas próximas aos 100 ha estudados mostraram a ocorrência de um espécime de Couratari tauari. Esta espécie até então, tinha sua ocorrência registrada apenas para região da Amazônia Central.

Comparação entre os inventários taxonômicos do pólo madeireiro central e do pólo madeireiro leste.

A diversidade das espécies foi maior na região da Amazônia Central, com destaque para Couratari stellata que apresentou uma população com estrutura agregada e a densidade relativa muito alta. As espécies Cariniana decandra e Couratari guianensis apresentaram densidade relativa muito baixa, sendo 


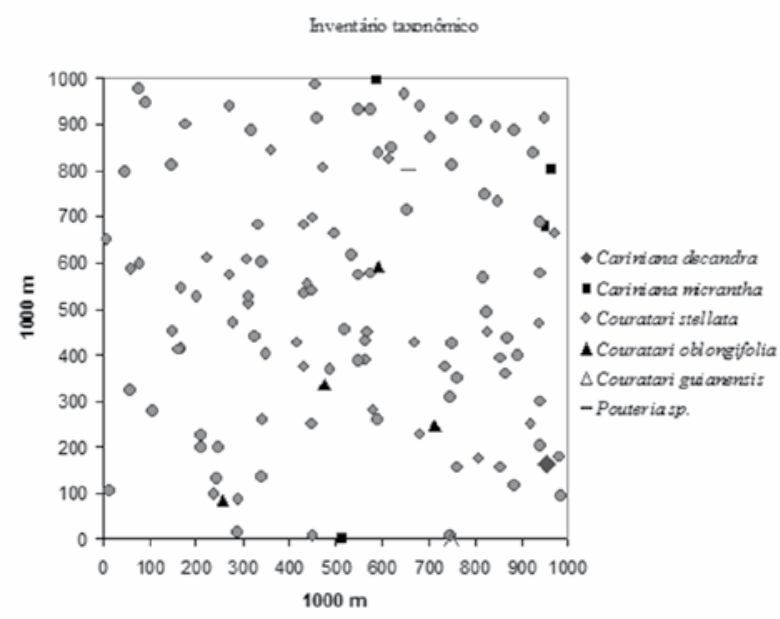

Figura 2 - Inventários taxonômico do Pólo Madeireiro Central - Floresta Nacional do Tapajós, Belterra - Pará.

um indivíduo para cada espécie nos 100 ha estudados (Figuras 2). Apenas C. guianensis e C. oblongifolia foram encontradas nas duas áreas estudadas, ambas com densidades relativas bem mais altas na região do pólo madeireiro leste (Figura 3).

No estudo realizado por Mori \& Lepsh-Cunha (1995), em uma parcela de 100 ha na Amazônia Central, com levantamento de espécimes de Lecythidaceae $\geq 10 \mathrm{~cm}$ de DAP, Couratari stellata e Cariniana decandra aparecem representadas com maior número de espécimes (Tab. 2). Comparando este estudo com os dados aqui apresentados podemos inferir que a população de $C$. guianensis apresenta densidades baixas e não agregadas em diferentes regiōes da Amazônia. Couratari stellata, apresenta população agregada e predomina em densidade relativa na Amazônia Central, sendo ausente, ou rara na Amazônia Oriental, já que nesta região não foi encontrado registro desta espécie. As espécies de Cariniana que aparecem com baixa densidade no levantamento do pólo madeireiro central, aparentemente têm tendência a elevar a densidade relativa em direção à região da Amazônia Ocidental. O oposto ocorre com Couratari oblongifolia, que apresenta poucos registros na região da Amazônia Ocidental e Central, sendo mais bem representada na Amazônia Oriental.

Os registros de herbários são utilizados na construção de mapas de ocorrência e distribuição geográfica das espécies (Fig 4). No entanto, somente os dados dos inventários mostram o comportamento das populaçōes em diferentes regiōes da Amazônia. A baixa densidade relativa de Couratari tauari demostra que os 200 ha estudados não foram suficientes para mostrar sua ocorrência e estrutura populacional. A coleta desta espécie, fora da área de estudo, na região do pólo madeireiro leste aparece como um novo registro de ocorrência para a Amazônia Oriental. Mesmo se considerado o esforço

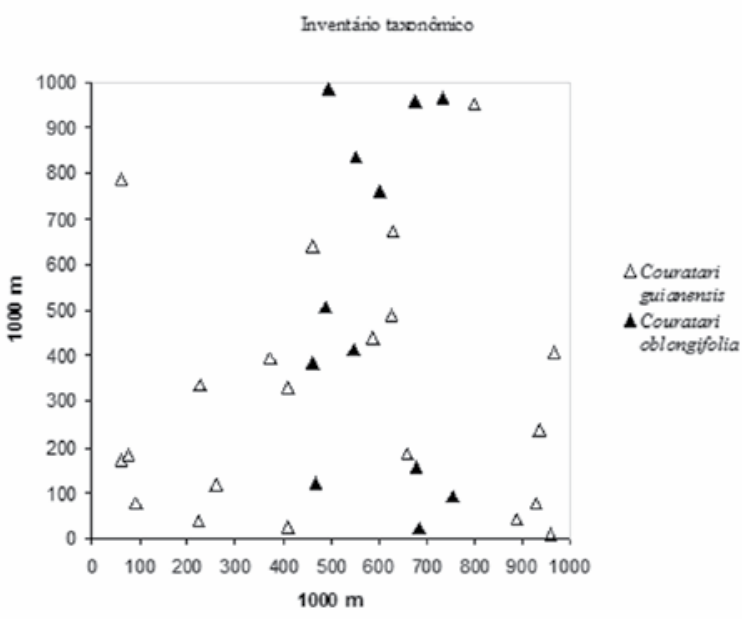

Figura 3 - Inventários taxonômico do Pólo Madeireiro Leste - Fazenda Rio Capim - Paragominas - Pará.

de coleta, esta espécie pode ser classificada como rara, pois existem poucos indivíduos nos inventários levantados e poucos registros nos herbários amazônicos visitados.

\section{CHAVE DE IDENTIFICAÇÃO E CARACTERIZAÇÃO DENDROLÓGICA DAS ESPÉCIES}

Caracteres de fuste e casca são importantes para separar as espécies. No entanto, caracteres das folhas em conjunto diminuem a probabilidade de erro na determinação das espécies deste grupo. É possível, com uma análise rápida dos caracteres destas espécies, construir uma chave consistente para este grupo.

Tabela 2 - Densidade relativa das espécies de "tauari" exploradas no Estado do Pará. Relative density of the logged species of "tauari" in the Pará State.

\begin{tabular}{lllllll}
\hline & $\begin{array}{l}\text { Pólo Leste (100 } \\
\text { ha) }\end{array}$ & \multicolumn{2}{l}{$\begin{array}{l}\text { Pólo Central (100 } \\
\text { ha) }\end{array}$} & $\begin{array}{l}\text { Amazônia } \\
\text { Central (100 } \\
\text { ha)* }\end{array}$ \\
\hline Espécie & $\begin{array}{l}\mathbf{N}^{\mathbf{*}} \\
\text { indv }\end{array}$ & DR (\%) & $\mathbf{N}^{\mathbf{0}}$ indv & DR (\%) & $\begin{array}{l}\mathbf{N}^{\mathbf{0}} \\
\text { indv }\end{array}$ & DR (\%) \\
\hline $\begin{array}{l}\text { Cariniana } \\
\text { decandra }\end{array}$ & 0 & 0,00 & 1 & 0,85 & 40 & 23,53 \\
$\begin{array}{l}\text { Cariniana } \\
\text { micrantha }\end{array}$ & 0 & 0,00 & 4 & 3,42 & 29 & 17,06 \\
$\begin{array}{l}\text { Couratari } \\
\text { guianensis }\end{array}$ & 21 & 63,64 & 1 & 0,85 & 21 & 12,35 \\
$\begin{array}{l}\text { Couratari } \\
\text { oblongifolia }\end{array}$ & 12 & 36,36 & 4 & 3,42 & 0 & 0,00 \\
$\begin{array}{l}\text { Couratari } \\
\text { stellata }\end{array}$ & 0 & 0,00 & 107 & 91,45 & 77 & 45,29 \\
$\begin{array}{l}\text { Couratari } \\
\text { tauari }\end{array}$ & 0 & 0,00 & 0 & 0,00 & 3 & 1,76 \\
total & $\mathbf{3 3}$ & & 117 & & 170 & \\
\hline
\end{tabular}

$\mathrm{N}^{0}$ indv=número de indivíduos encontrados; $\mathrm{DR}=$ densidade relativa * fonte: Mori \& Lepsch-Cunha (1995) 


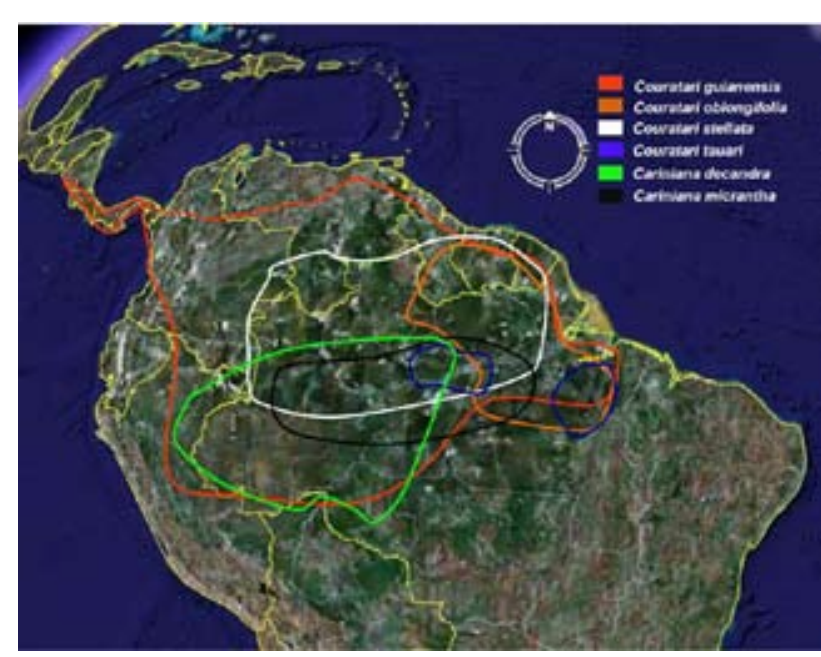

Figura 4 - Distribuição das espécies dos gêneros Couratari e Cariniana comercializados como "tauari" no Estado do Pará. Fonte: Mori \& LepschCunha (1995), Mori \& Prance (1990), Prance \& Mori (1979) e resultados da pesquisa. Imagem: Google Earth.

Chave de caracteres dendrológicos das espécies comercializadas como tauari no Estado do Pará.

1. Base do tronco com sapopemas tabulares altas $(>0,5 \mathrm{~m})$; casca com ritidoma que se desprende em placas papiráceo ou de cortiça. Ao corte, casca viva branca amarelada. $\ldots .2$

2. Folhas glabras ou pubérulas; pecíolo delgado, plano; base da lâmina não decurrente; ...3

3. Sapopemas $>2,5 \mathrm{~m}$ de altura. Folhas pequenas $5-9,5 \mathrm{~cm}$ compr.; lâmina oblanceoladas a obelíptica; margem inteira; venação de $2^{\mathrm{a}}$ ordem e superiores, pouco visíveis a olho nu na face adaxial. 4. Couratari oblongifolia

3' Sapopemas $<2,5 \mathrm{~m}$ de altura. Folhas grandes 12-13 cm compr.; lâmina oval a obovada; margem inteira e/ou irregular; venaçāo de $2^{a}$ ordem e superiores visíveis a olho nu na face adaxial.

6. Couratari tauari

2' Folhas pubescênte ou tomentosas, pecíolo grossso; base da lâmina decurrente ... 4

4. Folhas com margem inteira, pecíolo canaliculado, lâmina coriácea sem cicatrizes, obovada, raro oval, tomentosa com tricomas evidentes na face abaxial.

3. Couratari guianensis

4' Folhas com margem fortemente crenulada e ondulada; pecíolo alado, lâmina com cicatrizes formando 1 par de arcos paralelos a venação de $1^{\text {a }}$ ordem; tricomas estrelados presentes nos ramos jovens e venação na face abaxial .......

5. Couratari stellata

1'. Base do tronco sem sapopemas ou com sapopemas não tabulares baixas $(<0,5 \mathrm{~m})$; casca com ritidoma de difícil desprendimento. Ao corte, casca viva vermelha
5. Ramos lisos; pecíolo alado, folha oval a orbicular, margem inteira; venação de $3^{a}$ ordem inconspícua; lâmina sem cicatrizes e sem domácias na axila da venação de $2^{\mathrm{a}}$ ordem. 1. Cariniana decandra

5'. Ramos rugosos; pecíolo canaliculado a levemente alado, folha elíptica, margem crenulada; venação de $3^{a}$ ordem visíveis a olho nu; lâmina geralmente apresenta cicatrizes formando 1 par de arcos paralelos a venação de $1^{\text {a }}$ ordem; presença de domácias nas axilas da venação de $2^{\mathrm{a}}$ ordem.

\section{Cariniana micrantha}

\section{CARACTERIZAÇÃO DAS ESPÉCIES}

\section{Cariniana decandra Ducke}

Árvore $25-35 \mathrm{~m}$ alt., 45-250 cm DAP. Base do tronco sem sapopemas, raiz superficial longa, fuste cilíndrico (Fig. 5 e 6). Casca com ritidoma marrom a cinza, com padrōes de fissuras paralelas, sem desprendimento; ao corte, casca morta marrom-escura, grossa $(2 \mathrm{~cm})$; casca viva vermelha, fibrosa; alburno amarelo-esbranquiçado. Ramos velhos cinza, jovens marrom, aspecto liso, glabro; lenticelas poucas, minúsculas e inconspícuas. Folhas alternas; pecíolo 1-1,5 cm de compr., alado pela decurrência da lâmina, glabro. Lâmina $6-11,5 \mathrm{~cm}$ compr., cartácea, oval a orbicular, ápice curto-acuminado, base obtusa à arredondada; glabra e brilhante em ambas as faces, margem inteira. Venação eucamptodroma: $1^{\mathrm{a}}$ e $2^{\mathrm{a}}$ ordens salientes e as de $3^{\mathrm{a}}$ ordens planas, finas e inconspícua nas faces abaxial e adaxial.

Caracteres diagnósticos: ao corte, casca viva vermelha, fibrosa, alburno branco; folha com ápice acuminado e pecíolo plano, lâmina decurrente, margem inteira; venação de $2^{a}$ ordem arqueada, venação de $3^{a}$ ordem fina, inconspícua (pouco visível a olho nu); lâmina brilhante (Figs. 7, 11 a 14).

Amostras analisadas - Pará: Belterra, Rod. SantarémCuiabá Km 83, Flona Nacional do Tapajós, 02/XII/2003, st, L.C. Procópio et al. s.n, FNT 403777, (IAN 179510); 24 / IV/2002; st, L.C. Procópio s.n, FNT 403277, (IAN 179511); 03/XII/2003; st; L.C. Procópio s.n., FNT 607471, (IAN 179512); Amazonas: sem localização, II/1977, fl, M.R. Santos 97 (MG); Carauari, X/1980, fl, P. Lisboa, et al, 1867 (MG); V/1980, fl, A.S.L. da Silva et al. 889 (MG); Humaitá, V/1982, fl, L.O.A. Teixeira et al. 141 (MG).

\section{Cariniana micrantha Ducke}

Árvore (30)-40-(50) m alt., 80-100 cm DAP. Base do tronco sem sapopemas ou com sapopemas baixas $(10-50 \mathrm{~cm}$ de alt.), superficiais, arestas côncavas; fuste cilíndrico (Fig. 5 e 6). Casca com ritidoma marrom-escuro a cinza, com padrōes de fissuras rasas de difícil desprendimento; presença de lenticelas grandes espaçadas; ao corte, casca morta marrom-escura, grossa $(2 \mathrm{~cm})$, fibrosa; casca viva vermelha-clara, fina e fibrosa; 
alburno bege-claro a esbranquiçado. Ramos cinzas a marrons, aspecto rugoso, estriado, glabro com lenticelas horizontais, minúsculas, dispersas; gema na axila do pecíolo. Folhas alternas, pecíolo 0,3-(0,5) cm de compr., canaliculado. Lâmina 4,5-8,5 cm de compr., cartácea, elíptica, ápice acuminado, base cuneada, glabra, margem crenulada, algumas vezes com dentes escurecidos e com um par de cicatrizes paralelas a venação de $1^{\text {a }}$ ordem; venação eucamptódroma ou fracamente broquidódroma com domácias na axila da venação de $2^{\text {a }}$ ordem; na face abaxial; venação de $1^{\mathrm{a}} \mathrm{e} 2^{\mathrm{a}}$ ordens salientes e de $3^{a}$ ordem plana a impressa; na face adaxial: venação de $1^{a}$ e $2^{\mathrm{a}}$ ordem saliente, de $3^{\mathrm{a}}$ ordem fina, porém visível a olho nu.

Caracteres diagnósticos: árvore com casca levemente fissurada, fibrosa; ao corte, casca viva vermelha; folha com textura cartácea ápice acuminado e pecíolo não-decurrente, canaliculado; margem crenulada, às vezes com pontos escurecidos nos dentes e a lâmina com um par de cicatrizes paralelas a venação de $1^{a}$ ordem; venação de $2^{a}$ ordem próximas, oposta ou sub-oposta, com angulação reta em relação à venação primária; $3^{\mathrm{a}}$ ordem fina, inconspícuas, porém visível a olho nu; presença de domácias na axila da venação de $2^{a}$ ordem vistas na face abaxial. Cariniana micrantha e Couratari stellata possuem folhas bastante parecidas, porém é possível diferenciá-las pela textura coriácea, ausência de domácias na axila da venação de $2^{a}$ ordem e padrão de venação amarelada em folhas secas de $C$. stellata que não aparecem em C. micrantha (Figs. 15 a 18). A cor da casca viva é importante para separar estas duas espécies, vermelha nas Carinianas e esbranquiçadas nas Couratari (Figs, 7 e 10).

Amostras analisadas: Pará: Belterra, Rod. Santarém-Cuiabá Km 83, Flona Nacional do Tapajós; 03/XII/2003, st, L.C. Procópio et al. s.n., FNT 500820, (IAN 179513); 03/XII/2003, fr, L.C. Procópio et al. 512, FNT 500148, (IAN 178906); 27/IX/2002, st, M.P. Nascimento s.n., FNT 501864, (IAN 176858); Amazonas: Manaus, Reserva Ducke, 10/X/1996, fl, C.A. Sothers et al, 907 (MG, INPA); 17/XI/1995, fl, $A$. Vicentini \& E. Pereira 1157(MG, INPA); sem localização, $27 /$ X/1973, fl, C.C. Berg et al. 18145, (MG 29468); Rondônia, 15/XI/1968, fl, Prance 8499, (MG 39477).

\section{Couratari guianensis Aubl.}

Árvore (25)-30-(48) m alt., (50)-60-110 cm DAP. Base do tronco com sapopemas tabulares retas, raro côncavas, altas, (2)-5-(12) m alt., ramificadas; fuste reto ou acanalados; casca com ritidoma marrom-escuro a avermelhado, aspecto escamoso, desprendendo em pequenas placas papiráceas, leves estrias, pequenas lenticelas salientes na base; ao corte, casca morta marrom-avermelhada, fina $(0,5 \mathrm{~cm})$, fibrosa; casca viva de cor clara, variando da cor creme, passando pelo laranja-claro até vermelho-rosa, fina e fibrosa, com odor forte de linhaça; alburno amarelado. Ramo jovem marrom-claro, subglabros, ramos velhos marron-escuro com indumento tomentoso a ferrugíneo, cicatrizes salientes, geralmente com um par de estípulas no ápice dos ramos e na base do pecíolo $0,3-0,5 \mathrm{~cm}$ compr. Folhas alternas; pecíolo 1,0-1,5-(2) cm compr., grosso e canaliculado pela impressão da venação de $1^{\text {a }}$ ordem; lâmina (8)-11-14-(17) cm compr., coriácea, obovada, raro oval; ápice agudo; base obtusa a arredondada, decurrente; superfície abaxial tomentosa, ferrugínea na venação; superfície adaxial tomentosa na venação de $1^{\text {a }}$ ordem, geralmente brilhante, raro opaca; margem inteira; venação evidente broquidódroma, intramarginais descontínua; na face abaxial, venação de $1^{\text {a }}$, $2^{\mathrm{a}}$ e $3^{\mathrm{a}}$ ordens salientes; na face adaxial: de $1^{\mathrm{a}}$ ordem saliente, $2^{\text {a }}$ planas ou impressas.

Caracteres diagnósticos: árvore com casca marromavermelhada e sapopemas altas e ramificadas. Ao corte, casca viva branco-amarelada a laranja, fortemente fibrosa, cheiro acentuado de linhaça. Folha grande, coriácea, venação saliente e indumento bem evidente na face abaxial (Figs. 19 e 20).

Amostras analisadas: Pará: Moju, Rod. PA-150, Km 34; 22/X/2001, fr, D.P. Martins et al. 15, (IAN 175058); 22/ I/2003, st, M.P. Nascimento s.n., MOJU1069, (IAN 179505); 06/2002, fl, J.C. Freitas et al. 65 MOJU904 (IAN 175775); Fazenda Santa Marta, 27/VIII/2001, fr, L.C. Procópio et al. 426 (IAN 173158); 24/X/2002 JURUA-03-1606, st, M.P. Nascimento s.n. (IAN 179509); Paragominas, Fazenda Rio Capim, 18/IX/2002, st, M.P. Nascimento s.n., CIKEL0628411 (IAN 179508); Belém, 2/VII/1945, fl, A. Ducke 1933 (MG 18777); Portel; 6/VIII/1956, fl, R.L. Fróes 32943, (IAN 97396); Barcarena, 19/IX/1983, fr, M.R. Cordeiro 1810 (IAN 159511).

\section{Couratari oblongifolia Ducke \& Knuth}

Árvore 30-45 m alt., 30-70-(106) cm DAP. Base do tronco com sapopemas tabulares retas e côncavas, de 2,5-7 m alt., ramificadas; fuste cilíndrico; casca com ritidoma marromavermelhado à cinza, fissuras rasas desprendendo-se em placas retangulares com textura papirácea ou de cortiça; ao corte casca morta marrom-clara, fina $(<1 \mathrm{~cm})$, fibrosa; casca viva variando de bege-creme à rosada, em camadas escamosas; alburno amarelo-claro. Ramo marrom-escuro, de aspecto rugoso e com lenticelas pequenas, abundantes e dispersas; apresenta gemas axilares globosas e terminais em forma de rosetas cônicas. Folhas alternas e verticiladas no ápice dos ramos; pecíolo $0,8-(1,5) \mathrm{cm}$ compr., delgado e plano em secção transversão. Lâmina 4-7-(8,0) cm compr., coriácea, oblanceolada a obelíptica; ápice irregular de agudo a arredondado; base atenuada a cuneada, não decurrente; glabra; margem inteira; venação broquidódroma no ápice e eucamptódroma na base; na face abaxial: venação de $1^{\text {a }}, 2^{\mathrm{a}} \mathrm{e}$ $3^{\mathrm{a}}$ ordens salientes, intersecundárias evidentes; venação de $1^{\mathrm{a}}$ ordem grossa na base afinando em direção ao ápice; na face 


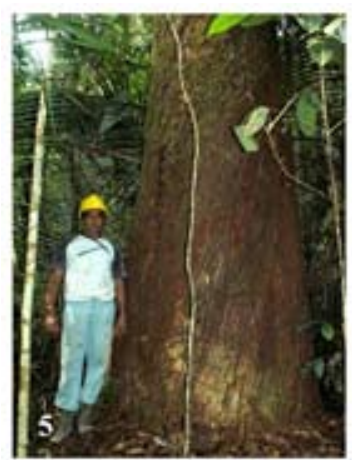

\section{Cariniana Aubl}

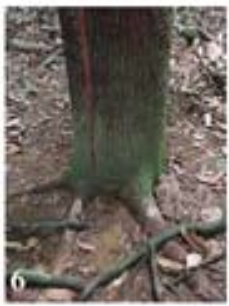

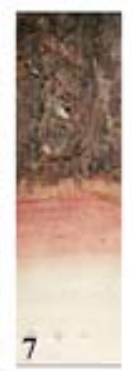

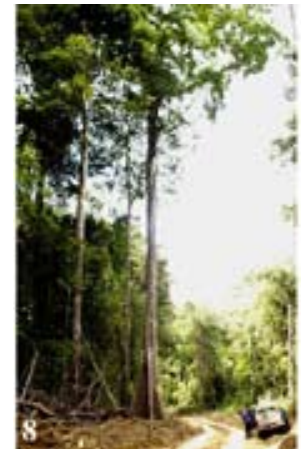

\section{Couratari Casar}

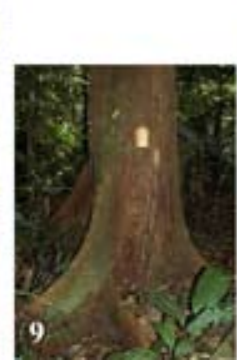

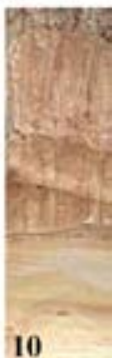

Figura 5 a 7 - Aspectos gerais das espécies de Cariniana: 5 e 6, base do tronco sem sapopemas tabulares; 7 casca avermelhada. 8 a 10 - Aspectos gerais das espécies de Couratari: 8 e 9, base do tronco com sapopemas tabulares, > 0,5 m de altura; 10 casca branca.
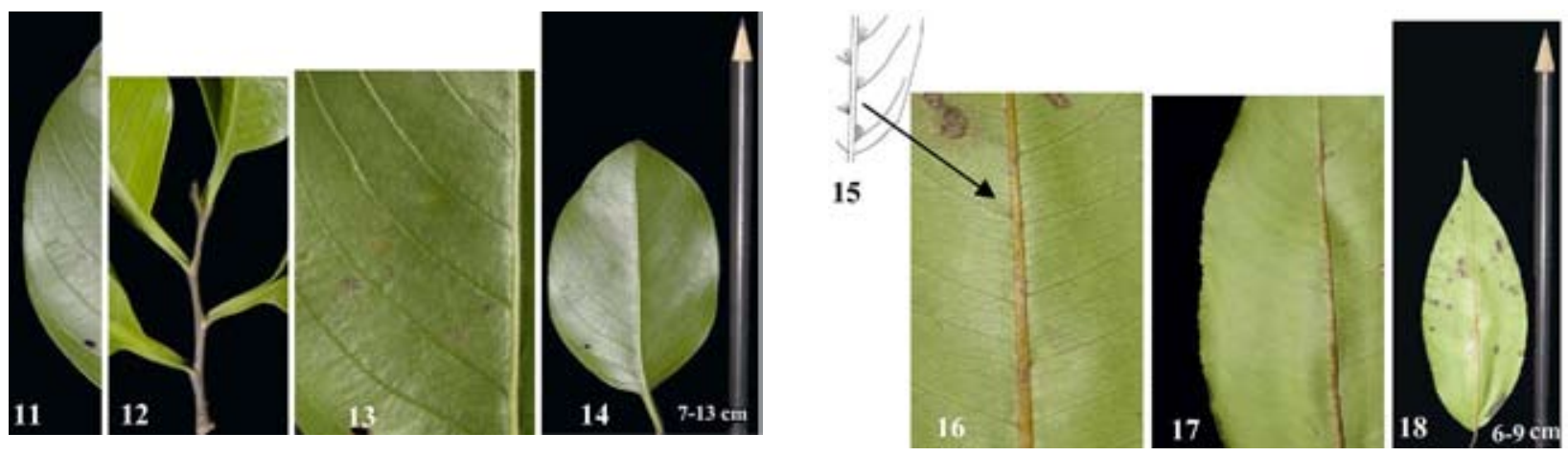

Figuras 11 a 14, Cariniana decandra, folhas grandes com margem inteira e venação de $3^{a}$ ordem pouco visível. 15 a 18, Cariniana micrantha, folhas pequenas com margem crenulada e domáceas na axila da venação de $2^{\mathrm{a}}$ ordem.
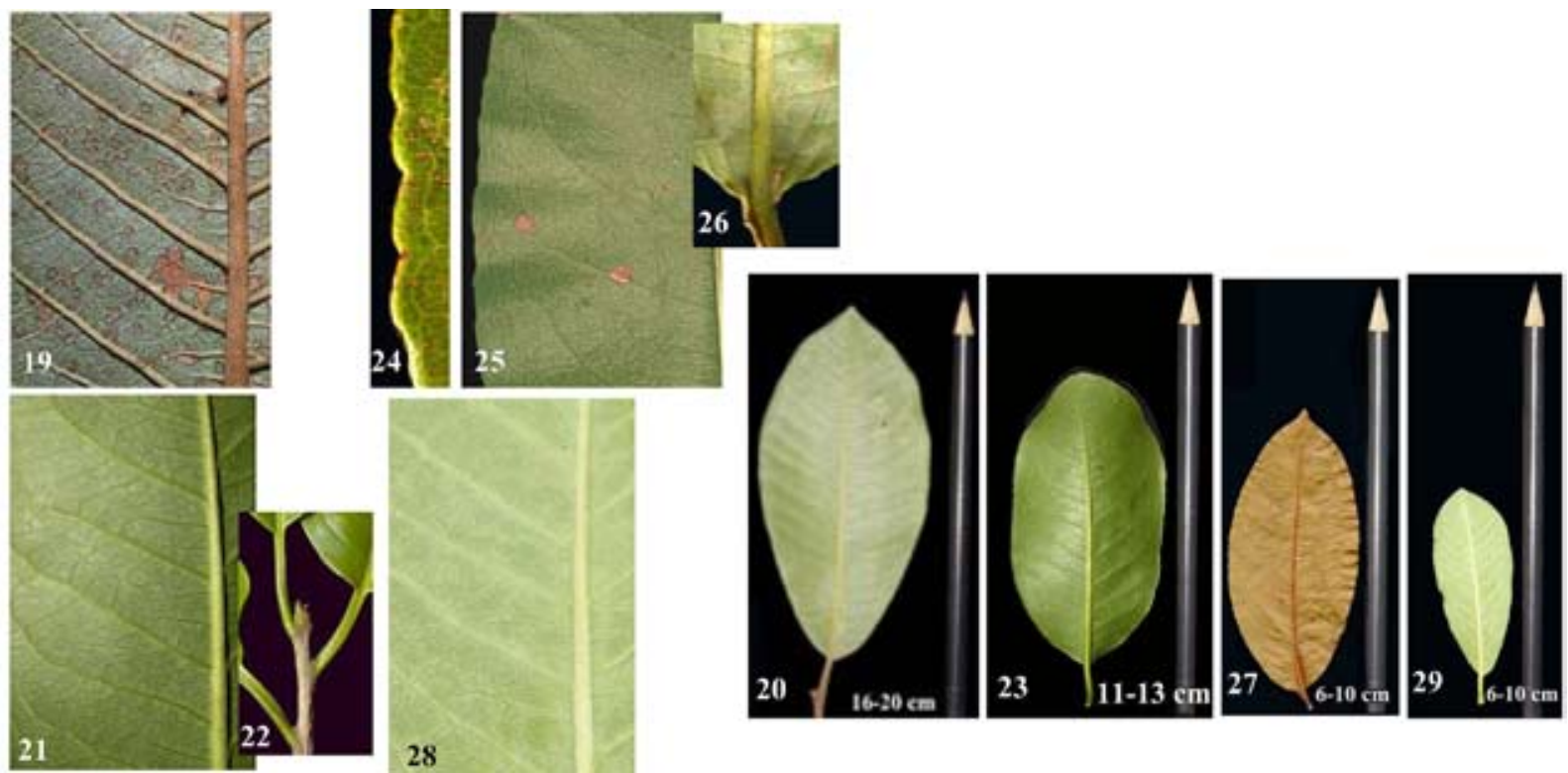

Figuras 19 e 20, Couratari guianensis, folhas tomentosa e de margem inteira, venação de $2^{\mathrm{a}}$ e $3^{\mathrm{a}}$ ordem bem evidente (cospícua). 21 a 23 Couratari tauari, folhas com margem inteira, pecíolo longo e plano. 24 a 27, Couratari stellata, folhas com margem crenulada e uma linha longitudinal na lâmina. 28 e 29, Couratari oblongifolia, folhas com margem inteira, venação de $2^{\mathrm{a}}$ e $3^{\mathrm{a}}$ ordem pouco evidente (incospícua). 
adaxial: venação de $1^{\text {a }}$ ordem plana ou levemente impressa, $2^{\mathrm{a}}$ ordem e superiores pouco visível a olho nu.

Caracteres diagnósticos: árvore com sapopemas altas, ramificadas; casca com ritidoma fissurado; ao corte, casca clara à rosada, fibrosa, em camadas escamosas; ramos densamente lenticelados com aspecto rugoso pela saliência das lenticelas; folhas agrupadas no ápice dos ramos com estípula apical em forma de roseta; presença de gema axilar; pecíolo longo e delgado; folhas com venação incospícua na face adaxial. (Figs. 28 e 29).

Amostras analisadas: Pará: Belterra, Rod. Santarém-Cuiabá Km 83, Flona Nacional do Tapajós, 2/XII/2003, st, L.C. Procópio et al. s.n, FNT 403130, (IAN 179514); 19/IV/2002, st, L.C. Procópio et al. s.n, FNT 400062, (IAN 179515); 24/ IV/2002, st, L.C. Procópio et al. s.n., FNT 403459, (IAN 179516); 7/XI/2003, st, M.P. Nascimento s.n, FNT 605486, (IAN 179506); 2/X/2001, st, R.N.S. Feitosa, s.n, ITTO 2575, (IAN 179503); Moju, Rod. PA-150, Km 34, I/2001, fl, L.C. Procópio et al. 376, MOJU136 (IAN 173496); 19/III/200, fr, M.P. Nascimento et al. 90 (IAN 175280); IX/2002, fr, J.C. Freitas et al. 85, MOJU994, (IAN 175929); Fazenda Santa Marta, 14/08/2002, st, M.P. Nascimento s.n, JURUA08-79, (IAN 179507); Paragominas, Fazenda Rio Capim, VIII/2002, fr, M.P. Nascimento et al. 127 (IAN 175839); 22/XI/2001, st, L.C. Procópio et al. s.n., CIKEL-LC-19, (IAN 179518); 29/V/2002, st, G.C. Ferreira 886, Cikel/FFT-04, (IAN 179504).

\section{Couratari stellata A.C.Smith}

Árvore (25)-35-(40) m alt., 35-80 cm DAP. Base do tronco circular com sapopemas tabulares assimétricas (até 3,5 $\mathrm{m}$ alt.); fuste cilíndrico à levemente acanalado. Casca com ritidoma marrom-escuro à bege, avermelhado na base com padrōes de fissuras superficiais, reticuladas desprendendo em poucas lâminas papiráceas; ao corte, casca morta marromescura, fina $(<1 \mathrm{~cm})$, fibrosa; casca viva laranja-avermelhada em camadas, finas e fibrosas; alburno amarelo-escuro. Ramos cinzas ou marrom-escuros, glabros; ramos jovens com tricomas estrelados, de aspecto rugoso; ramos apicais com gema protegida por estípulas finas, de forma linear, pubescente. Folhas alternas e dísticas; pecíolo (0,3-) 0,5-7,0 cm compr., alado com tricomas estrelados. Lâmina (4,5-) 5,5-8,5 cm, coriácea, obelíptica, raro oblongas; ápice agudo a cuspidado; base cuneada a arredondada, raro arredondada; tricomas estrelado na face abaxial; glabra na adaxial; margem crenulada e ondulada; um par de cicatrizes formando arcos paralelos a venação de $1^{\text {a }}$ ordem. Venação broquidódroma com intramarginais fechando-se em vários arcos. $\mathrm{Na}$ face abaxial: venação de $1^{\mathrm{a}}$ ordem saliente e grossa, $2^{\mathrm{a}}$ ordem saliente, finas, e de $3^{a}$ ordem planas; na face adaxial: venação de $1^{a}$ ordem fina, impressa em um canal; $2^{a}$ ordem saliente e fina, e de $3^{a}$ ordem plana.
Caracteres diagnósticos: árvore com sapopemas grandes, tabulares. Ritidoma com desprendimento laminar mostrando casca avermelhada. Ao corte, desprende casca fibrosa, em várias camadas. Folha com pecíolo alado, margem crenulada e ondulada, ápice agudo a cuspidado. Lâmina com um par de cicatrizes eqüidistantes, paralelas a venação de $1^{\circ}$ ordem. Tricomas estrelados, discretos, presentes nos ramos jovens e venação de $1^{\mathrm{a}}, 2^{\mathrm{a}} \mathrm{e} 3^{\mathrm{a}}$ ordem na face abaxial. A venação amarela se destaca nas folhas escuras, quando secas (Figs. 24 a 27).

Amostras analisadas: Pará, Belterra, Rod. SantarémCuiabá, 18/IX/1975, st, Erly IBDF079.6303, (IAN 150560); 23/IX/1975, st, IBDF084.6501, (IAN 150582); 09/X/1974, st, IBDF135.3304, (IAN150644); Rod. Santarém-Cuiabá, Km 83, Flona Nacional do Tapajós, 2/XII/2003, st, L.C. Procópio, FNT503704, (IAN 179517); 18/IV/2002, fr, G.J. Oliveira 07, FNT 603591 (IAN 175558); 17/IV/2002, fr, G.J. Oliveira 04, FNT 601640, (IAN 175555); 03/XII/2003, fl, L.C. Procópio \& Oliveira G.J. 505 (IAN 179403);29/IX/2001, st, R.N.S. Feitosa s.n, ITTO1672, (IAN 179502); Rod. Santarém-Cuiabá, Km 67, 6/III/1079, fr, M.R. Cordeiro et al. 1618 (IAN 155509); 31/X/1947, fl, G.A. Black 1907 (IAN 30107). Amazonas: Manaus, Reserva Ducke, 18/II/1998, fr, P.A.C.L. Assunção \& Pereira, 794 (IAN 171291); 10/II/1963 L.R. Marinho \& B.G.S. Ribeiro, 789 (IAN 162836); 3/ XII/1954, fl, R.L. Fróes 31200 (IAN 86943).

\section{Couratari tauari Berg}

Árvore 25-50 m de alt., 35-60 cm DAP. Base do tronco com sapopemas tabulares baixas (0,5-2 $\mathrm{m}$ alt.); fuste cilíndrico. Casca com ritidoma marrom-avermelhado, padrōes de estrias e desprendimento em pequenas placas irregulares; ao corte, casca morta marrom, fina $(1 \mathrm{~cm})$, fibrosa; casca viva amarela a creme com marcas semelhantes a chamas brancas, fibrosa, odor forte; alburno amarelo. Ramo marrom com aspecto rugoso; presença de lenticelas minúsculas, arredondadas e escuras; gema axilar cônica na base do pecíolo e gema apical com uma estípula linear de $0,3 \mathrm{~cm}$ compr. Folhas alternas; pecíolo $1,5 \mathrm{~cm}$ compr., plano. Lâmina 10,5-11,5 cm compr., coriácea, oval a obovada; ápice arredondado; base cuneada; face adaxial glabra e face abaxial pubérula; margem inteira, irregular, ondulada, levemente crenada; venação broquidódroma, eucamptódroma nas venaçôes basais; na face abaxial: venação de $1^{\text {a }}$ e $2^{\text {a }}$ e $3^{\text {a }}$ ordens fortemente salientes e evidentes; na face adaxial: de $1^{\text {a }}$, $2^{\mathrm{a}}$ e $3^{\mathrm{a}}$ ordem saliente a plana, visíveis a olho nu.

Caracteres diagnósticos: árvore com sapopemas tabulares baixas. Folhas fortemente broquidódromas, venação $2^{a}$ bastante visível a olho nu até as terminaçōes, planas na face adaxial; margem inteira, irregular, ondulada, levemente crenada; gema cônica na base do pecíolo (Figs. 21 a 23).

Amostras analisadas: Pará: Juriti Velho, fl, V/1927, Ducke s.n (Isolectotipo de Couratari duckei) (IAN 95932); Rio 
Trombetas, Sacará, V/1978, fl, N.T. Silva \& Santos 4653, (MG); Paragominas, Fazenda Rio Capim, Cikel, III/2002, fl, G. Ferreira \& Freitas 811 (IAN 175794).

\section{PROPRIEDADE E APTIDÃO TECNOLÓGICA DA MADEIRA}

Existem poucas informações sobre propriedades físicas da madeira de Couratari e Cariniana. Zeeuw (in Mori \& Prance, 1990) estudou a variabilidade na quantidade de sílica nos poros do xilema de Lecythidaceae Neotropicais. As espécies Cariniana decandra e C. integrifolia Ducke têm nos poros sílica em quantidades bem baixas ou algumas vezes ausentes. Para o gênero Couratari, a sílica está ausente em $C$. guianensis, enquanto em $C$. stellata é comum e de tamanho maior (comumente acima de $100 \mu \mathrm{m}$ ). A quantidade de sílica presente na madeira interfere principalmente na trabalhabilidade, tornando necessário o uso de equipamento especial no beneficiamento quando a quantidade de sílica é alta.

As informações sobre propriedades da madeira, publicadas pelo IBAMA/LPF (1991), abrangem somente três espécies de Couratari e uma de Cariniana (Tab. 3). Os dados apresentados são suficientes para perceber valores extremos entre as propriedades da madeira destas espécies comercialmente agrupadas em uma única. Couratari stellata aparece com índices de uma madeira mais dura e resistente, ao contrário de Couratari oblongifolia que apresenta a metade dos índices de C. stellata. Cariniana micrantha parece mais próxima de $C$. stellata em flexão estática e compressão, tração e cisalhamento, mas incompatível na dureza Janka.

\section{A LEGISLAÇÃO AMBIENTAL, A COMERCIALIZAÇÃO E A CONSERVAÇÃO DAS ESPÉCIES}

A elaboração de um plano de manejo florestal envolve decisões sobre número de árvores que podem ser retiradas e que devem ser mantidas como porta-sementes (Art. 7o. da LEI no 4.771 DE 15 DE SETEMBRO DE 1965 do Código florestal). Sendo assim, a identificação das espécies, bem como os conhecimentos sobre sua auto-ecologia devem ser precisos. No pólo madeireiro Central nota-se como o agrupamento de diferentes espécies afetou o conhecimento das populações, principalmente de Couratari guianensis e Cariniana decandra. Como consequência, não fica assegurada a sua condição de porta-sementes o que aumenta a probabilidade de desaparecimento destas na região da Floresta Nacional do Tapajós.

Para fins comerciais, além da segurança comprometida na aplicabilidade inadequada da madeira, entra em questião a relação de confiança entre comprador e vendedor. Divulgar e colocar no mercado espécies com seus respectivos valores tecnológicos pode amenizar a pressão de exploração de espécies intensamente extraídas.
Para fins de conservação, o plano de manejo deve considerar a diversidade e abundância das espécies em cada região e, para fins de comércio, as propriedades tecnológicas das espécies. Ou seja, se é necessário o agrupamento para a aquisição de uma cota de exploração suficiente para comercialização, que se faça o agrupamento conforme suas propriedades adequadas para o uso final, atentando para a importância da permanência de espécies menos abundante na região, assegurando assim a diversidade dos grupos.

Mesmo para fins de recuperação da área degradada, o conhecimento real das espécies que ali existiam antes da exploração é essencial, para não causar desequilíbrio ao ecossistema como um todo, evitando a introdução de espécies exóticas.

\section{CONCLUSÕES}

A identidade de uma planta possibilita a obtenção de informaçōes científicas sobre a mesma e a discussão do processo de sua conservação. Assim, não se pode manejar uma floresta sem conhecer a identidade das espécies que a compóe e, por conseguinte, sua auto-ecologia (p.ex. capacidade de regeneração natural, densidade relativa, etc).

A adoção de um único nome científico pelas empresas madeireiras para designar o grupo "tauari" mascara as informaçôes sobre a diversidade e densidade das espécies, impossibilita o conhecimento de estrutura da população, conseqüentemente, o planejamento do manejo florestal sustentável e compromete a relação de confiabilidade entre comprador-vendedor no uso final da madeira. Estudos ecológicos dependem de uma boa identificação botânica e estudos de silvicultura tropical dependem de informações ecológicas para sustentabilidade da exploração.

Uma identificação botânica com baixa margem de erro deve considerar o maior número de características de fuste, folhas e sempre que possível, flores e frutos em conjunto.

Finalmente, desde que o identificador botânico "mateiro" seja incentivando em sua formação, a identificação botânica deixará de ser vista como um obstáculo na construção dos inventários e passará a ser uma solução para manutenção da diversidade e sustentabilidade dos recursos florestais.

\section{AGRADECIMENTOS}

Aos financiadores deste estudo DFID, através do convênio com a Embrapa Amazônia Oriental no Projeto Dendrogene, bem como aos coordenadores deste Projeto, Milton Kanashiro e Ian Thompson, pelo apoio e por cederem as imagens apresentadas neste trabalho. Ao Conselho Nacional de Desenvolvimento Científico e Tecnológico - CNPq pela bolsa concedida no período de 2000-2004. As empresas madeireiras Cikel Brasil Verde e Maflops, pelo apoio logístico e técnico e 


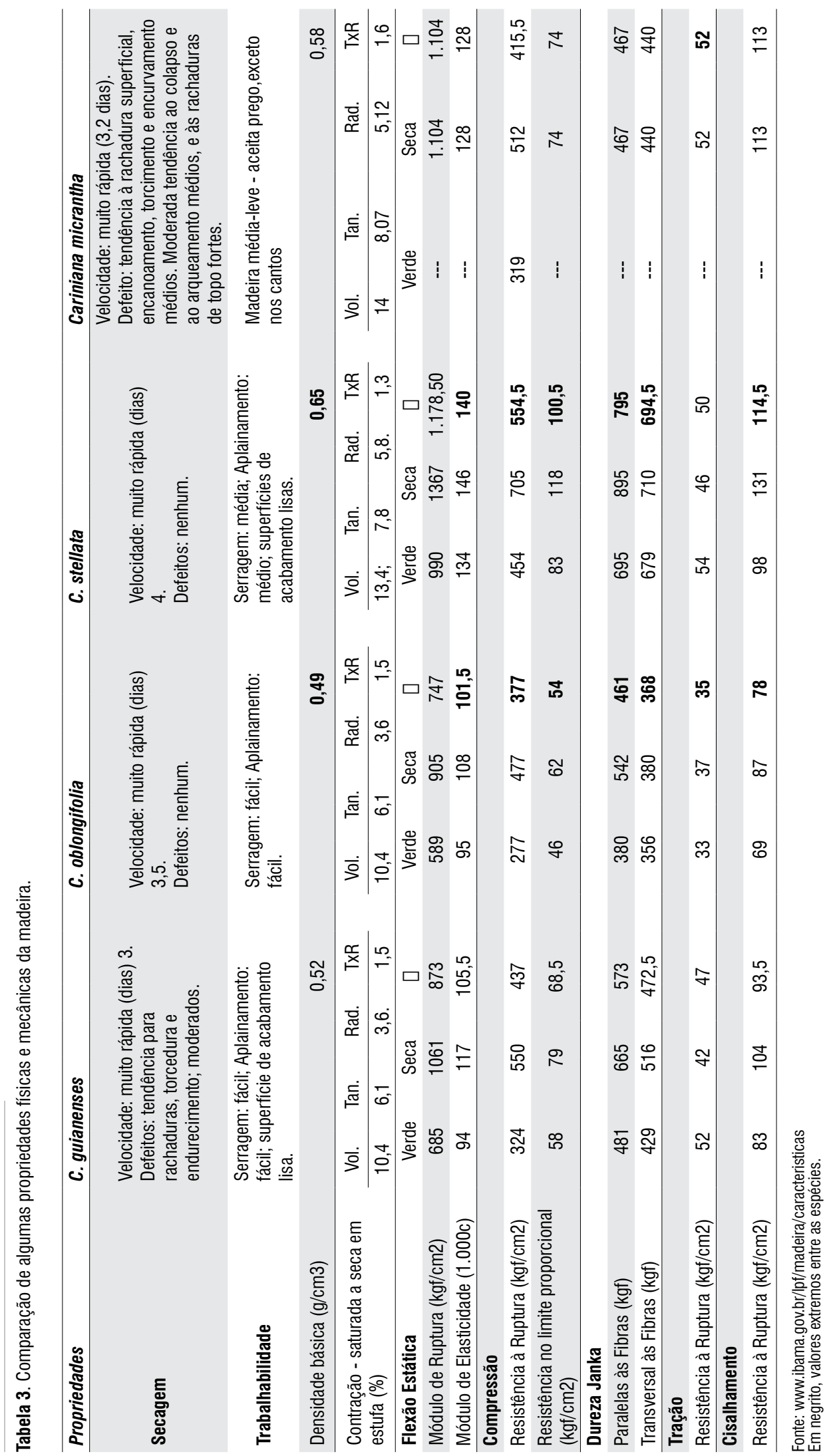

41 VOL. 38(1) 2008: 31 - 44 - PROCÓPIO \& SECCO 
pelo fornecimento dos inventários comerciais. Ao IBAMA, Núcleo Santarém pelo apóio logístico na Floresta Nacional do Tapajós através do Projeto ITTO. Ao museu Emilio Goeldi e a Universidade Federal Rural da Amazônia. Aos técnicos e identificadores botânicos do Projeto Dendrogene e do herbário IAN da Embrapa Amazônia Oriental, Manuel Cordeiro, Márcio Cordeiro, Jair Costa, João Oliveira e Miguel Nascimento. Aos pesquisadores Ricardo Secco, Michael Hopkins e Regina Célia Viana Martins-da-Silva pela orientação e finalmente aos revisores deste artigo e ao especialista Dr. Scott Mori, do NYBG pela identificação das amostras coletadas.

\section{BIBLIOGRAFIA CITADA}

Burger, L.M.; Richter, H.G. 1991. Anatomia da Madeira. Ed. Nobel. 154p. São Paulo.

Camargos, J. A.; Czarneski, C.M.; Meguerditchian, I.; Oliveira, D. de. 2001. Catálogo de árvores do Brasil. Brasília: IBAMA/ Laboratório de Produtos Florestais. Brasília. 643-644p.

IBAMA/LPF. Instituto Brasileiro de Meio Ambiente e dos Recursos Naturais Renováveis - Laboratório de Produtos Florestais. 1991. Padronização da Nomenclatura Comercial Brasileira da Madeiras Tropicais Amazônicas. Brasília. 59p.

IBAMA. Instituto Brasileiro de Meio Ambiente e dos Recursos Naturais Renováveis. Banco de dados de madeiras brasileiras. Disponível em <http://www.ibama.gov.br/lpf/madeira/resultado. php?idioma=portugues $>$. Acesso em 20 de setembro de 2003.

Kanashiro, M. 2002. As Diferenças entre as Árvores. Pesquisa FAPESP, no 82. São Paulo. 33pp.

Martins-da-Silva, R.C.V. 2002. Coleta e Identificação de Espécimes Botânicos. Embrapa Amazônia Oriental, Doc. 143. Belém. 40p.

MMA. Ministério do Meio Ambiente. 2002. Instrução Normativa $N^{o}$ 4, de 4 de março de 2002. Diário Oficial $N^{o} 45$, de 7 de março de 2002. Dispõe: Capítulo I - Da exploração das florestas da Bacia
Amazônica; Capítulo II - Das sanções administrativas e penais; Capítulo III. Das disposições gerais e transitórias

Mori, S.A.; Prance, G.T. 1990. Lecythidaceae-Part II: The zygomorphicflowered New World genera (Couroupita, Corythophora, Bertholletia, Couratari, Eschweilera, \& Lecythis), with a study of secondary xylem of Neotropical Lecythidaceae. Flora Neotropica. Monograph 21(2) - New York Botanical Garden. New York. $1-376 \mathrm{p}$.

Mori, S. A.; Lepsch-Cunha, N. 1995. The Lecythidaceae of a Central Amazonian Moist Forest - Memoirs of the New York Botanical Garden. New York. 75:1-29p.

Prance, G.T.; Mori, S.A. 1979. Lecythidaceae-Parte I: The actinomorphic-flowered New World Lecythidaceae (Asteranthos, Gustavia, Grias, Allantoma \& Cariniana). Flora Neotropica Monograph 21 - New York Botanical Garden. New York. $1-270 \mathrm{p}$.

Ribeiro, J.E.L. da S.; Hopkins, M.J.G.; Vicentini, A.; Sothers, C.A.; Costa, M.A. da S.; Brito, J.M. de; Souza, M.A.D. de; Martins, L.H.P.; Lohmann, L.G.; Assunção, P.A.C.L.; Pereira, E. da C.; Silva, C.F. da; Mesquita, M.R.; Procópio, L.C. 1999. Flora da Reserva Ducke: Guia de identificação das plantas vasculares de uma floresta de terra-firme na Amazônia Central. Manaus: INPA, 816p.

Silva, J.N.M. 2001. Manejo Florestal. Embrapa Amazônia Oriental , 3a. ed. Belém.49p.

SUDAM/IPT. Superintendência de Desenvolvimento da Amazônia Instituto de Pesquisa Tecnológicas. 1981. Rendimento em Serraria de Trinta Espécies de Madeiras Amazônicas. Belém. 185p.

Vasconcelos, F.J.; Freitas, J.A.; Castro e Silva, A. 1993. Observaçōes microscópicas de inclusōes minerais

no xilema de espécies tropicais da Amazônia. Acta Amazonica. Manaus. 25 (1/2): 55-68p

Veríssimo, A.; Lentini, M.; Lima, E. 2002. Pólos madeireiros do Estado Pará. Imazon. Belém. 75p.

Recebido em 18/10/2006

Aceito em 23/11/2007 